\title{
Simulated Space Environment Effects on the Blocking Force of Silicone Adhesive
}

Paul Boeder (Boeing), Ron Mikatarian (Boeing), Steve Koontz (NASA JSC), Keith Albyn (NASA MSFC), Miria Finckenor (NASA MSFC)

\begin{abstract}
The International Space Station (ISS) solar arrays utilize MD-944 diode tape to protect the underlying diodes in the solar array panel circuit and also provide thermal conditioning and mechanical support. The diode tape consists of silicone pressure sensitive adhesive (Dow Corning QC-7725) with a protective Kapton over-layer. Onorbit, the Kapton over-layer will erode under exposure to atomic oxygen (AO) and the underlying exposed silicone adhesive will ultimately convert, under additional AO exposure, to a glass like silicate.
\end{abstract}

The current operational plan is to retract ISS solar array P6 and leave it stored under load for a long duration ( 6 months or more) during ISS assembly. With the Kapton over-layer eroded away, the exposed silicone adhesive must not cause the solar array to stick to itself or cause the solar array to fail during redeployment. Previous testing by LockheedMartin Space Systems (LMSS) characterized silicone blocking following exposure to low energy atomic oxygen (AO) in an asher facility, but this is believed to be conservative. An additional series of tests was performed by the Environmental Effects Group at Marshal Space Flight Center under direction from the ISS Program Office Environments Team. This test series included high energy $\mathrm{AO}(5 \mathrm{eV})$, near ultraviolet (NUV) radiation and ionizing radiation, singly and in combination. Additional samples were exposed to thermal energy $\mathrm{AO}(<0.1 \mathrm{eV})$ for comparison to the LMSS tests.

Diode tape samples were exposed to each environment constituent individually, put under preload for seven days and then the resulting blocking force was measured using a tensile machine. Additional samples were exposed to AO, NUV and electrons in series and then put under long term (three to ten months) preload to determine the effect of preload duration on the resulting blocking force of the silicone-to-silicone bond.

Test results indicate that high energy AO, ultraviolet radiation and electron ionizing radiation exposure all reduce the blocking force for a silicone-to-silicone bond. AO exposure produces the most significant reduction in blocking force. 


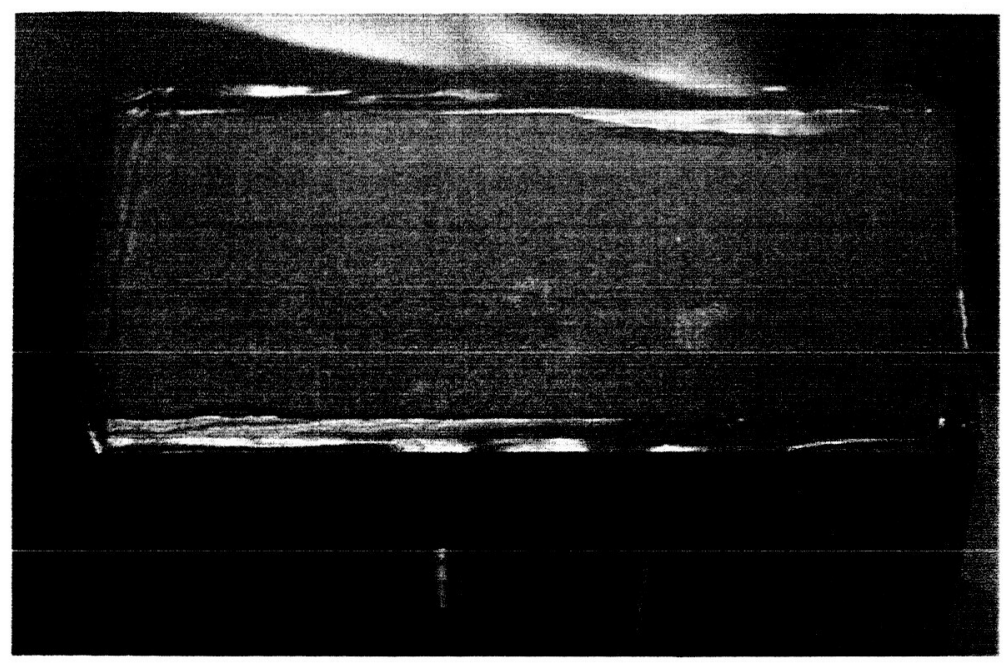

Figure 1. MD-944 diode tape sample, pre-exposure.

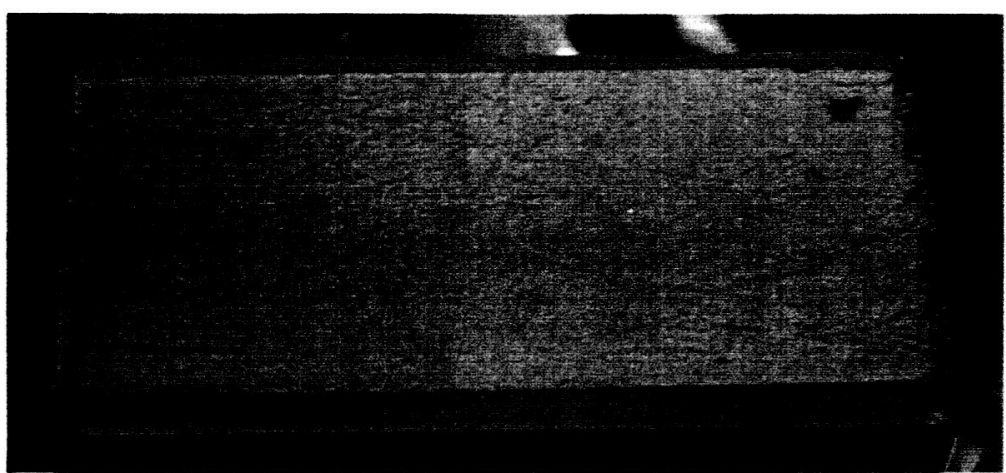

Figure 2. Diode tape sample following exposure to a total $5 \mathrm{eV}$ AO fluence of $1.48 \times 10^{21} \mathrm{atoms} / \mathrm{cm}^{2}$. No blocking force was observed for this sample. 


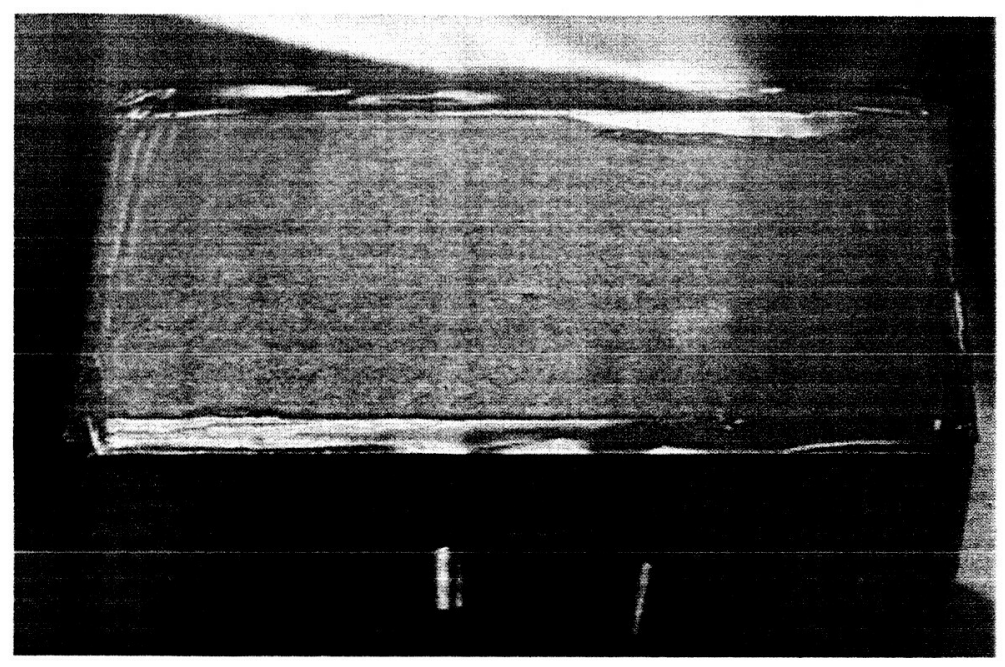

Figure 1. MD-944 diode tape sample, pre-exposure.

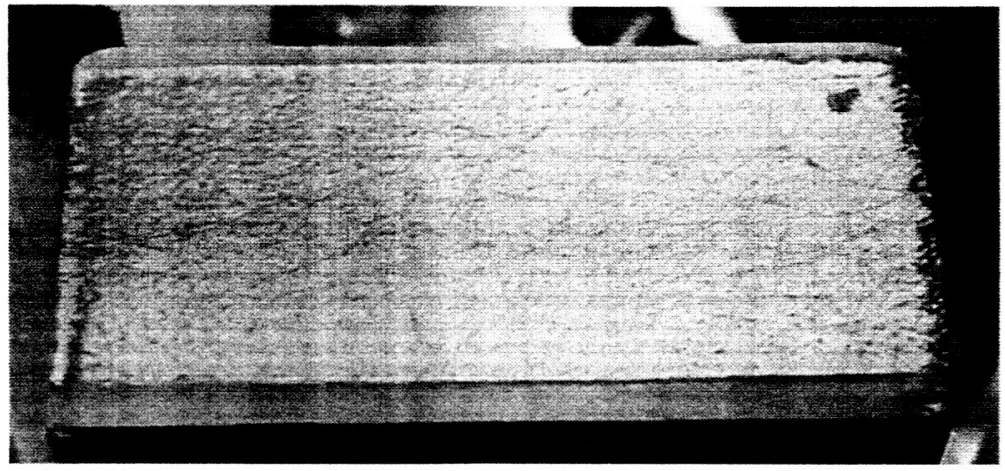

Figure 2. Diode tape sample following exposure to a total $5 \mathrm{eV} \mathrm{AO}$ fluence of $1.48 \times 10^{21}$ atoms $/ \mathrm{cm}^{2}$. No blocking force was observed for this sample. 